Review Article

\title{
Tuberculosis: still a way to go ahead for a lead-a review
}

\begin{abstract}
Although decades of worship bring a light of new chemical classes and moieties for the treatment of tuberculosis and still running to enlighten more possible ways to withstand and draw a full stop to the condition, the standard reports of tuberculosis enlisting cases are still on the increment side rather to declining state. Since 90 s the regimen of anti-TB drugs is well established but now it is under red alters concern as the drugs are resistant to the causative bacilli, M. tuberculosis, endangering mostly the developing countries and disease prone areas of the world. With the motivation of new drug approved for the disease, the moieties in the pipe line for the consideration of being a successful drug, the review also concerns about possible new classes for lead optimization process along with repurposed drugs trial.
\end{abstract}

Keywords: bedaquiline, delamanid, HIV, anti-TB, investigational moieties, drug discovery, lead, MDR
Volume 5 Issue 6 - 2017

\author{
Priyanka Bose,' Amit K Harit, ${ }^{2}$ Kamal \\ Krishna Halder ${ }^{3}$ \\ 'Department of Pharmaceutical Sciences, Dr. H. S. Gour Central \\ University, India \\ ${ }^{2}$ Deptartment of Chemistry, Dr. H. S. Gour Central University, \\ India
}

Correspondence: Priyanka Bose, Dept. of Pharmaceutical Sciences, Dr. H. S. Gour Central University, Sagar, MP-470002, India, Email meow.bose@gmail.com

Received: June 25, 2017 | Published: August 23, 2017

\section{Introduction}

During a decade and a half, a worldwide concept of High Burden Country (HBC) has gained a recognized position in the different documented context of $\mathrm{Tb}$ produced till date. In 2015, after the TB strategy modification and upgradation process by WHO, a new three HBC list has been defined to be used for the period of 2016-2020 enlisting $85-89 \%$ of the global burden and category details of each country. In this list, 14 countries have been mentioned to be the most prone zone of TB with increasing case and recurrence of TB with other additional health risk. ${ }^{1}$ With the time, the TB cases are getting more complicated associating other diseases as well like HIV, MDR etc. The causative organism is a facultative one well known, Mycobacterium tuberculosis now with different modified virulent strains. TB mostly affects adults in their productive year besides; children can get affected at early stage of age 0-14 years also leading to drastic cases if not treated at time. Over $95 \%$ cases are of developing countries. In 2015 the largest amount of TB cases reported from Asia with $61 \%$ of new cases followed by Africa with $26 \%$. Very common symptoms of TB are the cough with sputum and blood at times, besides, chest pain, weight loss, fever and night sweats. ${ }^{1-4}$ In 2010 WHO first recommended the use of rapid test Xpert MTB/RIF® which simultaneously detects TB and resistance to rifampicin which is one of the first line drugs for the tuberculosis treatment. In 2016, four new diagnostic tests had been recommended by WHO, i.e., a rapid molecular test to detect TB where Xpert MTB/RIF ${ }^{\circledR}$ cannot be used and other three to detect resistance to first and second line TB medicines, like, Beacon assay (use ultrasensitive PCR technique for M. tuberculosis complex and rifampicin resistance), the GeneXpertTB assay (automated assay process), molecular line probe assay (use PCR and revised hybridization process for rapid detection of mutation associate with drug resistance, Isoniazid and Rifampicin). ${ }^{2,5}$ Newly introduced other detections are, loop mediated isothermal application (TB-LAMP) for pulmonary tuberculosis diagnose and lateral flow urine lipoarabinomannam assay (LF-LAM) for diagnose and screening of active tuberculosis patients with HIV. ${ }^{5}$

Depending on the zone the treatment regimen for each country has some specific regimen which is being followed in that specific country and zone as all the countries have their own margin of condition. Here, the standard regimen recommended by WHO in 1997 for the tuberculosis treatment which is only modified in complex cases which has been later discussed, is as follows.

\begin{tabular}{|c|c|c|c|}
\hline \multirow[b]{2}{*}{ Treatment Category } & \multirow[b]{2}{*}{ Clinical Condition } & \multicolumn{2}{|l|}{ TB regimen } \\
\hline & & $\begin{array}{l}\text { Intensive } \\
\text { Phase }\end{array}$ & $\begin{array}{l}\text { Continuous } \\
\text { Phase }\end{array}$ \\
\hline Category I & $\begin{array}{l}\text { - New (untreated) smear positive pulmonary } \\
\text { TB. } \\
\text { - New smear negative pulmonary TB with } \\
\text { extensive parenchymal involvement. } \\
\text { - New cases of severe forms of extra } \\
\text { pulmonary TB. }\end{array}$ & $2 \mathrm{H}_{3} \mathrm{R}_{3} \mathrm{Z}_{3} \mathrm{E}_{3} / \mathrm{S}_{3}$ & $4 \mathrm{H}_{3} \mathrm{R}_{3}$ \\
\hline Category II & $\begin{array}{l}\text { - Smear positive relapse. } \\
\text { - Smear positive treatment failure. } \\
\text { - Interrupted treatment cases. }\end{array}$ & $\begin{array}{l}2 \mathrm{H}_{3} \mathrm{R}_{3} \mathrm{Z}_{3} \mathrm{E}_{3} \mathrm{~S}_{3}+ \\
\mathrm{IH}_{3} \mathrm{R}_{3} \mathrm{Z}_{3} \mathrm{E}_{3}\end{array}$ & $5 \mathrm{H}_{3} \mathrm{R}_{3} \mathrm{E}_{3}$ \\
\hline Category III & $\begin{array}{l}\text { Smear negative pulmonary TB with limited } \\
\text { parenchymal involvement or less form of extra } \\
\text { pulmonary Tb. }\end{array}$ & $2 \mathrm{H}_{3} \mathrm{R}_{3} \mathrm{Z}_{3}$ & $4 \mathrm{H}_{3} \mathrm{R}_{3}$ \\
\hline
\end{tabular}

Where, $\mathrm{H}$, isoniazid; $\mathrm{R}$, rifampicin; $\mathrm{Z}$, pyrazinamide; $\mathrm{E}$, ethambutol; S, streptomycin 
Next comes another threat that is, HIV patients, who are 20-30 times more susceptible to develop active TB disease causing a lethal condition ensuring each other's aggressive progression and one third of the HIV patients worldwide has been reported with TB as well, in the enlisting of TB cases by WHO in 2015. About 35\% death among HIV positive people were out of TB condition and about 1.2 million new cases of TB has been reported with HIV positive cases among which $71 \%$ cases are from African region. ${ }^{1-3,6,7}$ The worst condition of tuberculosis is the multi-drug resistant tuberculosis (MDR-TB) in which the bacteria doesn't respond to Isoniazid and Rifampicin, the two most important first line drug of the regimen so it can only be treated with second line drug and extensive chemotheraphy which are expensive and highly toxic. Besides these, extensively drug resistant TB (XRD-TB) is a more critical condition in which the bacilli become resistant to the second line drugs as well leaving no option of treatment. About 480000 people worldwide have enlisted as MDR TB patient in 2015, and about $9.5 \%$ of these are XRD TB in the report of the WHO. In 2016, WHO approved a new drug regimen for the MDR TB condition which doesn't involve the strains of the bacilli resistant to second line drugs taken 9-12 months which taken up to 2 years. But XRD TB patients cannot use these; however, they are required to take longer MDR TB regimens to which one new drug, i.e., Bedaquiline (i) and Delamanid (ii), may be added in Figure 1.,3,4,7

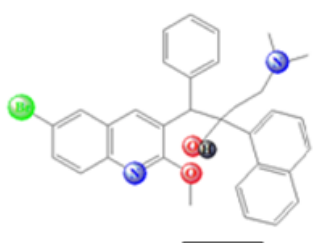

(i)

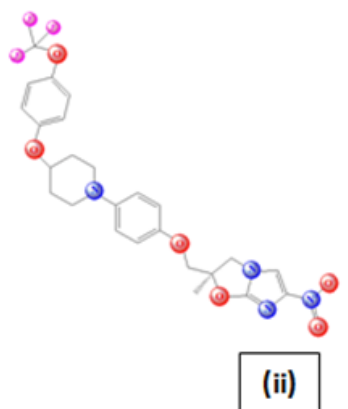

Figure I Chemical structure of Bedaquiline and Delamanid.

\section{Discussion}

With time the burden condition need to be reduced to reach nullification point of TB patient worldwide which is the prime aim of WHO for these session, the keen effort put to light on the present situation and future possible prospective to achieve this thoughtful objective.

\section{New drugs approved}

Bedaquiline: In 2012, 28th of December, US FDA granted the approval of Johnson and Jhonson's drug bedaquiline formerly known as TM207 or R207910 for treating resistant cases prevalently in India, China and Eastern Europe. The diarylquinoloine classed moiety hinders the proton pump of mycobacterial Adenosine Triphosphate (ATP) synthase enzyme, which is a crucial enzyme for ATP synthesis of the bacilli. The moiety targets the oligomeric and proteolipic subunit $\mathrm{C}$ of the enzyme leading to the cease of ATP synthesis subsequently death of the targeted cell. Besides these another approach for its mode of action has been depicted, i.e., it also binds to the epsilon subunit of the $\mathrm{F}_{0} \mathrm{~F}_{1}$ ATP synthase of the bacilli. The best eye streaming thing is this drug is equipotent to replicating and dormant phase of the $M$. Tuberculosis bacilli ${ }^{8-21}$ Figure 2.

Delamanid: With the requirement of critical condition management, though having a chance of resistant but not in sense prompt adaptation, due to the prodrug nature of the moeity, it has received the global approval for use in combination with an optimized background anti-TB regimen for MDR-TB in the EU and also is under review for marketing approval in Japan for same indication, in $2014,28^{\text {th }}$ of April, developed by Otsuku company. Chemically it is a nitro-dihydro-imidazooxazole which requires nitro-reduction intra-cellularly by $\mathrm{F}_{420}$-deazaflavin-dependent nitro-reductase present in $M$. tuberculosis, to produce the des-nitro-imidazooxazole form which is the active form, brings hindrance to the synthesis of methoxy mycolic and ketomycolic acid, the essential cell wall components of the targeted causative microbe. Besides, it is also being reported that a reactive intermediate metabolite formed between delamanid and des-nitro-imidazooxazole derivative plays a vital role in the inhibition of mycolic acid production of the cell. It has explicit documentation for having potent Invitro and invivo activity against both drug susceptibility and drug resistant strains of the bacilli with the plus advantage of no cross resistance and antagonist effect with the first line drugs. It also promotes intracellular generation of microbiocidal nitrogen oxidative intermediates including nitric oxides (NO) which can be the predominant encounter of the dormant condition as well. ${ }^{22-}$ 34

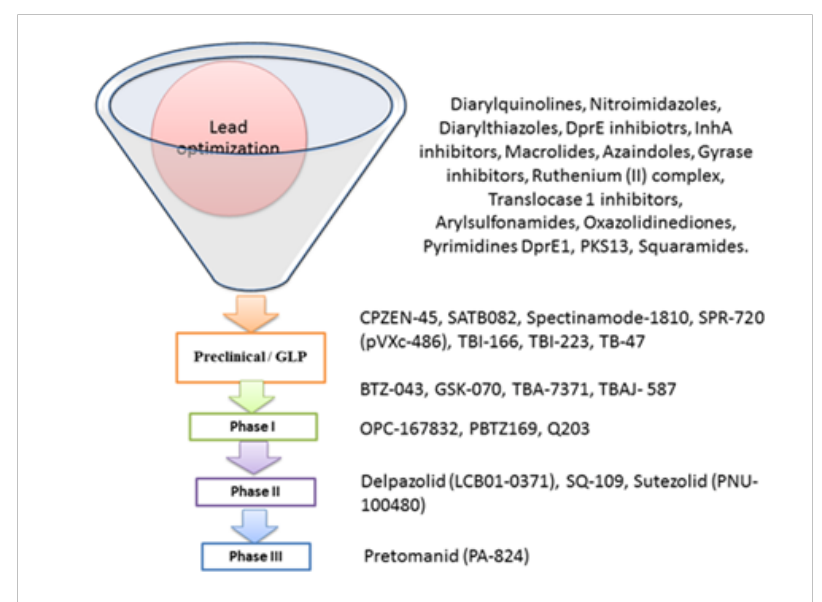

Figure 2 Current pipeline of compounds for drug establishment as Anti-TB agent.

[Details of the project can be found at http://www. newtbdrugs.org/pipeline/clinical and ongoing projects without a lead compound series identified can be viewed at http://www.newtbdrugs.org/pipeline/discovery]

\section{Currently using classes for lead optimization and precilinc trial}

Nitroimidazole (Figure 3a): This class of drug has been explored to a great and has contributed to new era anti-TB drug, delamanid which is indicated for multi-drug resistance tuberculosis by WHO in 2014. Besides this another molecule known as PA-824 also called Proteomanid is under clinical trial phase three. The activity of the molecule is restricted to the complex situation as well there is a number of laboratory mutants have shown resistant to it in which the ability of producing $\mathrm{F}_{420}$ cofactor is lost and the drug remains inactive in the cell. Metronidazole which is a marketed product with other indication was under investigation but due to high dose leading to severe high rates of peripheral neuropathy occurrence so it is put out of the plot. ${ }^{35-38}$

Ethylene-diamine (Figure 3b): Ethambutol of the standard anti-TB regimen is an ethylene-diamine class drug but in the real scenario 
it is considered to be a weak one among the total drug combination so a better potent moiety is being searched over and SQ109 gets its way to real molecular world but its long term trial hasn't assured its destined anti-TB efficacy so still not a drug. SQ109 hinders the action of MmpL3, an essential membrane protein which transport trehalose monomycolate into the cell envelope. So it inhibits genesis of mycolic acid of cell wall instead of inhibiting arabinosyl transferase which is the prime action ethumbutol. ${ }^{39-42}$

Benzothaizinones (Figure 3c): This class of chemical moieties has been reported to be potent at nanomolar level concentration in vitro and ex-vivo condition and so considered to be one of the most critical molecular spatial belonging from the pipeline of TB drug discovery. BTZ043 is a potent candidate of the chemical class and active against drug susceptibility, MDR and XDR cases of the disease. The mode of action for the class is inhibition of decaprenyl-phosphorylbeta-D-ribose 2'-epimerase (DprE1) enzyme which catalyzes the conversion of decaprenyl-phosphoryl-D-ribose to decaprenylphosphoryl-D-arabinose, the uttermost important arabino precursor for the synthesis of essential cell wall components, arabinogalactan and lipoarabinomannan in turn causes the hindrance the cell wall synthesis leading to bacterial mortality. BTZ043 undergoes nitroreduction in physiological environment and inhibits DprE1 enzyme covalently through a cysteine residue of the active site. Advantage of this molecule is it doesn't have shown any antagonist action to the other drugs of the anti-TB regimen and as well with some molecules under the trials like, PA-824, SQ109. ${ }^{43-48}$

Oxazolidinedione (Figure 3d): Linezolid is well known drug of this category molecular entity but on potency and safety concern a better molecule sutezolid also referred as PNU-100480 is the pipeline drug of anti-TB drug challenge as linezolid on long term use is associated with neuropathy and myelo-suppression. On the contrary sutezolid doesn't cause such effect and bactericidal effect is twice. The prime encounter mode of the chemical entity is through the protein synthesis inhibition of the bacilli. Another potent compound of this class, also have come on the timeline with the research investigation effort, is AZD5847 which is highly effective in intracellular bacilli as well as extracellular cells to that of linezolid without showing antagonism effect to the anti-TB regimen dugs which indicates to the development of the moiety, which has specific protein synthesis hindrance activity as the prior mechanism for anti-TB effect. ${ }^{49-57}$

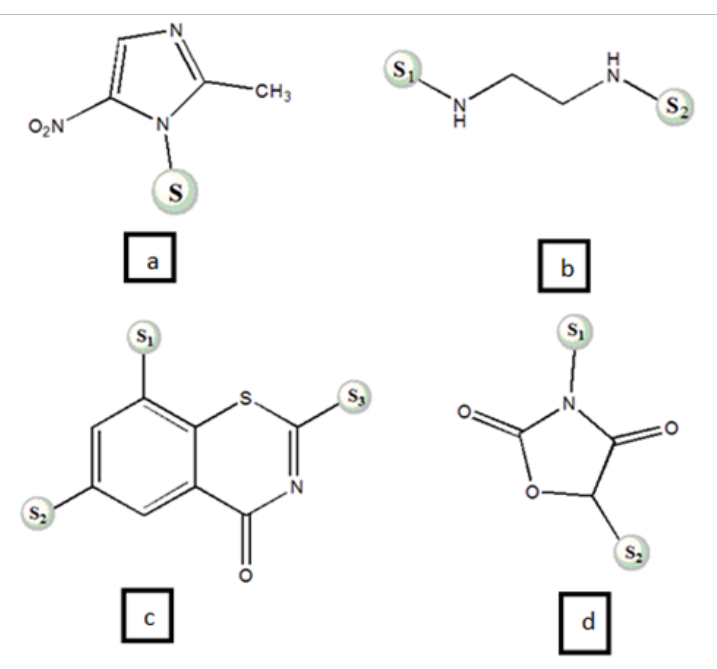

Figure 3 Basic chemical structure of the lead optimizing classes (pipeline classes).

\section{Newly synthesized compounds for lead determination}

N'-nicotinoyl-3-(4'-hydroxy-3'-methyl phenyl)-5-[(sub) phenyl]2-pyrazolines (Figure 4a): A series of compounds of this class has been reported and were screened for the anti-TB activity among them $40 \%$ compound has shown $\mathrm{MIC}<1 \mu \mathrm{M}$ and found to be more potent than the standard drugs. ${ }^{58}$

Thiazolylhydrazone derivatives (Figure 4b): All the synthesized compounds of the series was highly potent with the ability of more than $90 \%$ hindrance to the growth of the bacilli along with least or none cytotoxicity has been reported within the range of MIC (MIC > $6.25 \mu \mathrm{g} / \mathrm{ml}){ }^{59}$

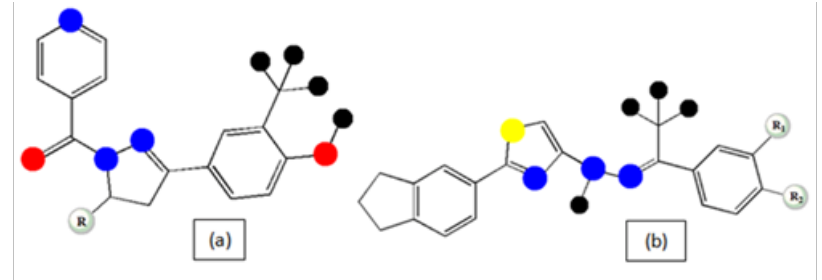

Figure 4 Basic chemical structure of N'-nicotinoyl-3-(4'-hydroxy-3'-methyl phenyl)-5-[(sub) phenyl]-2-pyrazolines (a) and Thiazolylhydrazone derivatives (b).

4-Benzylsulfanylpyridine-2-carbohydrazides (Figure 5a): The pyridine-2-carbohydrazides derivatives of 4-Benzylsulfanyl has been synthesized in a series and the results reflects significant potential of the compounds to hinder the growth of $M$. avium and $M$. kansassi My $235 / 80$ which are isoniazid resistant with low values MIC in $\mu \mathrm{mol} / \mathrm{L}$ unit with the advantage of less anti-proliferative and cytotoxic effect. ${ }^{60}$

Benzothiazolo naphthyridone carboxylic acid derivatives (Figure 5b): The newly substituted derivatives of Benzothiazolo naphthyridone proclaims to be more active than isoniazid (first line and primary drug) and Gatifloxacin (second line drug) as well as it is potent for the MDR-TB condition as well in the MIC value range of 0.04 to $6.06 \mu \mathrm{M}$ which urges for a more attention towards this series development. ${ }^{6}$
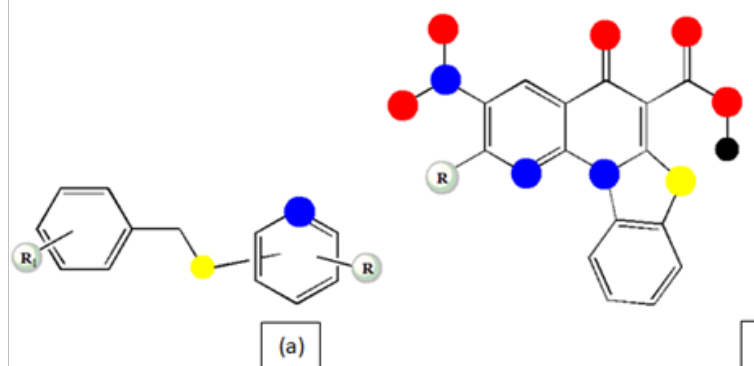

(b)

Figure 5 Basic chemical structure of 4-Benzylsulfanylpyridine-2 carbohydrazides (a) and Benzothiazolo naphthyridone carboxylic acid derivatives (b).

5-nitrothiazolylthiosemicarbazones (Figure 6a): The sensible versatile approach towards the semicarbazone derivative synthesis has bought to a conclusion that all the compound of this synthetic series screened against seven Mycobacterium species (M. tuberculosis, M. smegmatis ATCC14468, M. microti MTCC1727, M. vaccae MTCC997, M. phlei MTCC1724, M. fortuitum MTCC951, M. kansassi MTCC3058) shows moderate to high potency than INH with less cytotoxicity report with less MIC value range for each condition and argues for the development of the series and brings in lime of lead optimization step. ${ }^{62}$ 
5-(aryl/cyclohexylsulfanyl)-2-alkoxy-4,6-diarylnicotinonitriles (Figure 6b): The synthesized new variants of nicotinonitriles has been indicated for the potency more than pyrazinamide (first line drug) and ethumbutol (second line drug) with less potency than isoniazid against M. tuberculosis strain. ${ }^{63}$

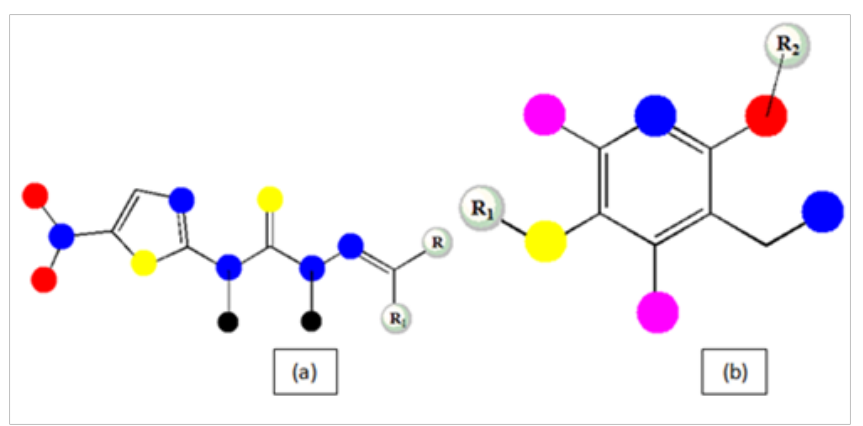

Figure 6 Basic chemical structure of 5-nitrothiazolylthiosemicarbazones (a) and 5-(aryl/cyclohexylsulfanyl)-2-alkoxy-4,6-diarylnicotinonitriles (b).

Isoniazid analogues (Figure 7a): A series of compounds are produced for the evaluation which reflects more potent compound development with less MIC values (MIC $<10 \mu \mathrm{M}$ ) with a range of compounds which proclaims for research lime light fall. ${ }^{64}$

Isoniazid derivatives from renewable fatty acid (Figure 7b): in the structure of the conventional proto anti-TB drug both saturated and unsaturated fatty acid chains has been incorporated resulting in improvement in antimicrobial activity with appreciable MIC values. Compound, produced from palmitic acid, could a turning point for the new antibiotic era is being reported. ${ }^{65}$

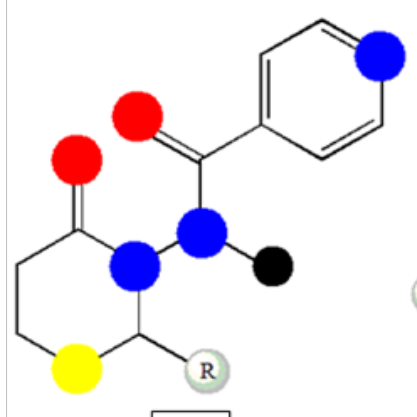

(a)

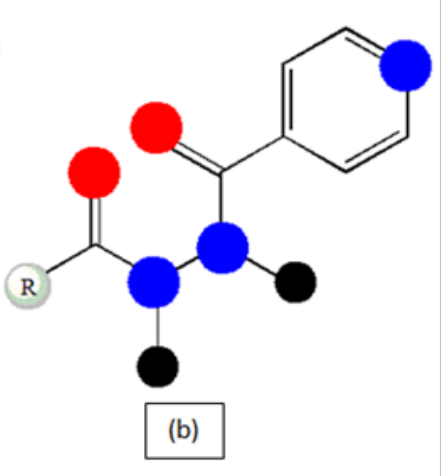

Figure 7 Basic chemical structure of Isoniazid analogues (a) and Isoniazid derivatives from renewable fatty acid (b).

2,4-diaminoquinazoline derivatives (Figure 8 \& 9): this versatile series has an attention drawing microbiological profile with bactericidal activity against replicating and non-replicating $\mathrm{M}$. tuberculosis encouraging for the development of the series for bacterial viability. ${ }^{66}$

\section{Repurposed drugs}

Already present antibiotic drug moieties in the market but indicated primarily for different disease is now being under the consideration for TB drug development process. ${ }^{67,68}$ Linezolid (Figure 10a) was trialed for many years as an anti-TB drug molecule but now for the toxicity profile and low safety measures, it has been on hold and the other moieties of same class under being considered for studies. ${ }^{67}$ Meropenem (Figure 10b) which is a carbapenem antibiotic indicated for bacterial disease presently, has been reported for having a promising potential and safety profile of acceptable limits in a case control study of tuberculosis. ${ }^{69}$ Co-trimoxazole (Figure 10c) which is an antibiotic of early stage antibiotic era has been reported for potent activity in multi-drug resistant tuberculosis treatment. ${ }^{70}$ Moxifloxacin (Figure 10d) which has shown an appreciable activity along with other standard anti-TB drug can be a potent component in the regimen for drug sensitive tuberculosis for its safety profile and no intractability measures. ${ }^{71}$ Nextly, one is the NSAID class compounds which are magical and wonder drugs are being evaluated and found to be potent anti-TB active, specifically,carprofen (Figure 10e) has shown the least MIC values. The efficacy, safety, toxicity and acceptability have reviewed on the animal models which conclude to potentially useful for alleviating the symptoms of TB. ${ }^{72}$

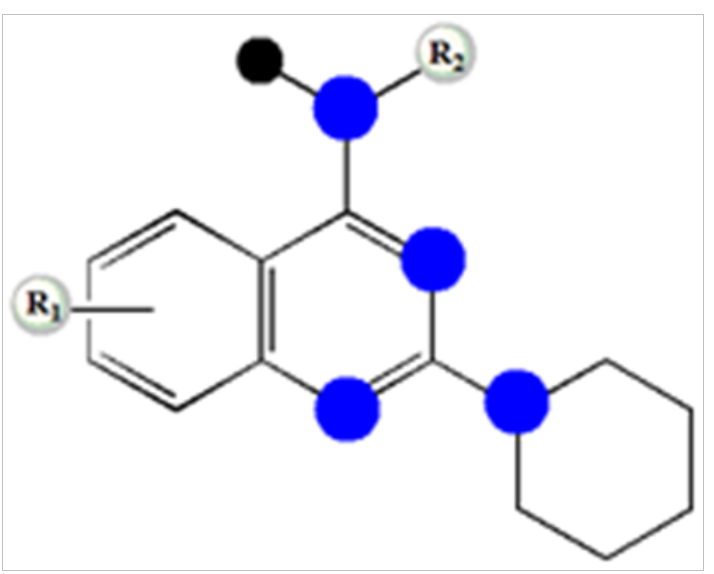

Figure 8 Basic chemical structure of 2,4-diaminoquinazoline derivatives.

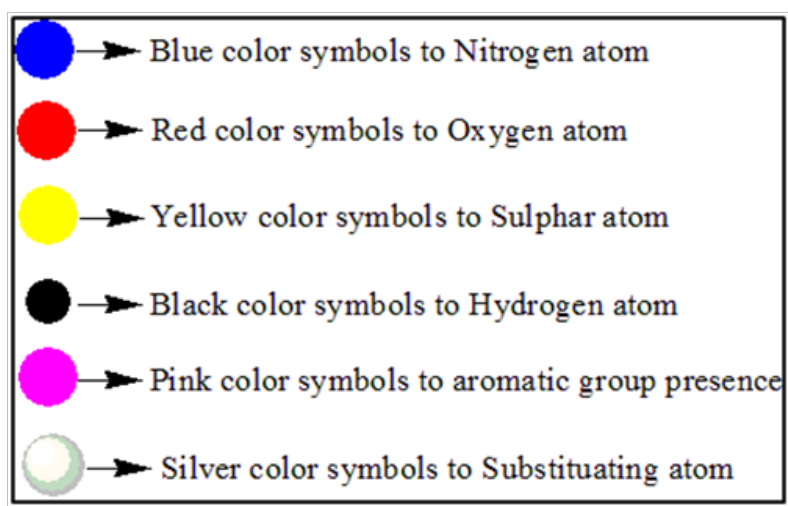

Figure 9 Symbol details used to specify atomic structures in the molecular system.

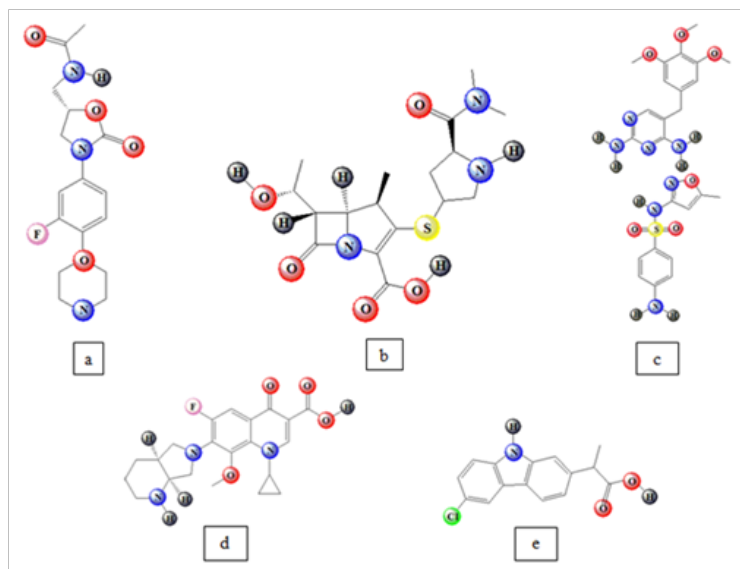

Figure 10 Chemical structure of the repurposed drugs for tuberculosis treatment. 


\section{Conclusion}

Former discussion already has cleared the efforts are being done by different scientists and researchers to find a new time line compounds or a group of compounds with advantages of using in a proper delivery means in single or combination form to establish a new regimen for the cure of present complex conditioned tuberculosis cases. It will be better approach if a group of drugs of different classes with different potential biological activity without inter-interactivity or affect the dosing of each other in in-vivo condition should be the next approach for the cure, treatment and maintenance for the disease. The mechanism of action of the new drugs should be on those bio molecular structures which don't have alternative pathways easily but not present in human body cells as well but crucial for the bacteria to survive and also defines the bacteria to be the characteristic cell. Those protein structures should be the target site for the drug molecules. Besides another attempt should be made on the molecules which are already present as bactericidal should be checked for their activity on the M. tuberculosis, there resides a possibility that may some molecule has capacity to interact in different way from the reported and known ways. All these means should be fettered in a productive fledge to explicate a way to the treatment for decades.

\section{Acknowledgments}

None.

\section{Conflicts of interest}

No conflict of interest.

\section{References}

1. http://www.who.int/tb/publications/global_report/en/

2. http://www.who.int/mediacentre/factsheets/fs104/en/

3. www.who.int/tb/country/data/profiles/en/

4. http://www.who.int/tb/publications/global_report/high_tb_ burdencountrylists2016-2020summary.pdf?ua=1

5. http://www.who.int/tb/WHOPolicyStatementSLLPA.pdf

6. https://www.health.ny.gov/diseases/chronic/basicstat.htm

7. http://www.unaids.org/en/resources/fact-sheet

8. https://www.wsj.com/articles/SB100014241278873233204045782134 21059138236

9. Matteelli A, Carvalho AC, Dooley KE, et al.TMC207: The first compound of a new class of potent anit-tuberculosis drug. Future Microbiol. 2010;5(6):849-858.

10. https://www.fda.gov/

11. Mahajan R. Bedaquiline: First FDA-approved tuberculosis drug in 40 years. Int J Appl Basic Med Res. 2013;3(1):1-2.

12. Goel D. Bedaquiline: A novel drug to combat multiple drug resistant tuberculosis. J Pharmacol Pharmacother. 2014;5(1):76-78.

13. Andries K, Verhasselt P, Guillemont J, et al. A diarylquinoline drug active on ATP synthase of Mycobacterium tuberculosis. Science. 2005;307(5707):223-227.

14. Koul A, Dendouga N, Vergauwen K, et al. Diarylquinolines target subunit C of mycobacterial ATP synthase. Nat Chem Biol. 2007;3(6): 323-324.

15. Koul A, Vranckx L, Dendouga N, et al. Diarylquinolines are bactericidal for dormant mycobacteria as a result of disturbed ATP homeostatis. $J$ Biol Chem. 2008;283(37):25273-25280
16. Rustomjee R, Diacon AH, Allen J, et al. Early bactericidal activity and pharmacokinetics of the diarylquinolines TMC207 in treatment of pulmonary tuberculosis. Antimicrob Agents Chemother. 2008;52(8):2831-2835.

17. Rao SP, Alonso S, Rand L, et al. The protonmotive force is required for maintaining ATP homeostasis and viability of hypoxic nonreplicating Mycobacterium tuberculosis. Proc Natl Acad Sci USA. 2008;105(33):11945-11950.

18. Haaagsma AC, Abdillahi-Ibrahim R, Wagner MJ, et al. Selectivity of TMC207 towards microbacterial ATP synthase compared with that towards the eukaryotic homologue. Antimicrob Agents Chemother. 2009;53(3):1290-1292.

19. Diacon AH. The diarylquinoline TMC207 for multiple drug resistant tuberculosis. N Engl J Med. 2009;360:2397-2405.

20. Huitric E, Verhasselt P, Koul A, et al. Rates and Mechanisms of Resistance Development in Mycobacterium tuberculosis to a Novel Diarylquinolines ATP synthase Inhibitor. Antimicrob Agents Chemother. 2010;54(3):1022-1028.

21. Diacon AH, Donald PR, Pym A, et al. Randomized pilot trial of eight weeks of bedaquiline (TMC207) treatment for multidrug resistant tuberculosis: Long-term outcome, tolerability, and effect on emergence of drug resistance. Antimicrob Agents Chemother. 2012;56(6):32713276 .

22. Kawasaki M. Mechanism of action of OPC-67683 against M tuberculosis, Interscience Conference on Antimicrobial Agents and Chemotheraphy (ICAAC), Washington, DC: Poster F-1463, USA. 2005.

23. Doi N. Characteristic antimicrobial spectra of the novel anti-TB drug candidates $O P C-67683$ and PA-824. Interscience Conference on Antimicrobial Agents and Chemotheraphy (ICAAC), San Francisco CA: Poster F1-F1337a, USA. 2006.

24. Tuberculosis (Ednib). OPC-67683. 2008;88(2):132-133.

25. Mastumoto M, Hashizume H, Tomishige T, et al. OPC-67683, a nitro dihydro imidazooxazole derivative with promising derivatives with promising action against tuberculosis In vitro and in mice. PLoS Med. 2006;3(11):e466.

26. Singh R, Manjunatha U, Boshoff HI, et al. PA-824 kills nonreplicating Mycobacterium tuberculosis by Intracellular NO release. Science. 2008;322(5906):1392-1395.

27. Gler MT, Vija Skripconoka, Epifanio Sanchez-Garavito, et al. Delamanid for Multidrug Resistant Pulmonary Tuberculosis. $N$ Engl J Med. 2012;366:2151-2160.

28. Diacon AH, Dawson R, Hanekom M, et al. Early bactericidal activity of delamanid (OPC-67683) in smear positive pulmonary tuberculosis patients. Int J Tuberc Lung Dis. 2011;15(7):949-954.

29. Skirpconoka V, Danilovits M, Pehme L, et al. Delamanid improves outcomes and reduces mortality in multidrug resistant tuberculosis. Eur Respir J. 2013;41(6):1393-1400.

30. Field SK. Safety and efficacy of Delamanid in the treatment of Multidrug-Resistant Tuberculosis (MDR-TB). Clinical Medicine Insights: Therapeutics. 2013;5:137-149.

31. Ryan NJ, Lo JH. Delamanid: First Global Approval. Drugs 74(9): $1041-$ 1045.

32. Xavier AS, Lakshmanan M (2014) Delamanid: A new armor in combating drug-resistant tuberculosis. J Pharmacol Pharmacother. 2014;5(3):222-224.

33. Lewis JM, Sloan DJ. The role of Delamanid in the treatment of drug resistant tuberculosis. Ther Clin Risk Manag. 2015;11:779-791. 
34. Rustomjee R, Zumla A. Delamanid expanded access novel treatment of drug resistant tuberculosis. Infect Drug Resist. 2015;8:359-366.

35. Manjunatha UH, Lahiri R, Randhawa B, et al. Mycobacterium leprae is naturally resistant to PA-824. Antimicrob Agents Chemother. 2006;50(10):3350-3354.

36. Lin PL, Dartois V, Johnston PJ, et al. Metronidazole prevents reactivation of latent Mycobacteriumtuberculosis infection in macaques. Proc Nat Acad Sci USA. 2012;109(35):14188-14193.

37. Strover CK, Warrener P, VanDevanter DR, et al. A small molecule nitroimidazopyran drug candidate for the treatment of tuberculosis. Nature. 2000;405(6789):962-966.

38. Carroll MW, Jeon D, Mountz JM, et al. Efficacy and safety of metronidazole for pulmonary multidrug resistant tuberculosis. Antimicrob Agents Chemother. 2010;54(8):3402-3407.

39. Lee RE, Protopopova M, Crooks E, et al. Combinatorial lead optimization of [1,2]-diamines based on ethumbutol as potential antituberculosis preclinical candidates. J Comb Chem. 2003;5(2):172-187.

40. Nikonenko BV, Protopopova M, Samala R, et al. Drug therapy of experimental tuberculosis (TB): improved outcome by combining SQ109, a new diamine antibiotic, with existing TB drugs. Antimicrob Agents Chemother. 2007;51(4):1563-1565.

41. Reddy VM, Einck L, Andries K, et al. In vitrointeractions between new antitubercular drug candidates SQ109 and TMC207. Antimicrob Agents Chemother. 2010;54(7): 840-2846.

42. Tahlan K, Wilson R, Kastrinsky DB, et al. SQ109 targets MmpL3, a membrane transporter of trehalose monomycolate involved in mycolic acid donation to cell wall core of Mycobacterium tuberculosis. Antimicrob Agents Chemother. 2012;56(4):1797-1809.

43. Makarov V, Manina G, Mikusova K, et al. Benzothiazinones kill Mycobacteriumtuberculosis by blocking arabinan synthesis. Science. 2009;324(5928):801-804.

44. Neres J, Pojer F, Molteni E, et al. Structural basis for benzothiazinone mediated killing of Mycobacterium tuberculosis. Sci Transl Med. 2012;4(150):150ra121.

45. Trefezer C, Rengifo-Gonzalez M, Hinner MJ, et al. Benzothiazinones: prodrug that covalently modify the decaprenyl-phosphoryl-beta-Dribose 2'-epimerase DprE1 of Mycobacterium tuberculosis. J Am Chem Soc. 2010;132(39):13663-13665.

46. Christophe T, Mary Jackson, Hee Kyoung Jeon, et al. High content screening identifies decaprenyl-phosphoryl-beta-D-ribose 2'-epimerase as a target for intracellular antimicrobial inhibitors. PLoS Pathogens. 2009;5:e1000645

47. Pasca MR, Degiacomi G, Ribeiro AL, et al. Clinical isolates of Mycobacterium tuberculosis in four Europen hospitals are uniformly susceptible to benzothiazinones. Antimicrob Agents Chemother. 2010;54(4):1616-1618.

48. Lechartier B, Hartkoorn RC, Cole ST. In vitro combination studies of benzothiazinones lead compound BTZ043 against Mycobacterium tuberculosis. Antimicrob Agents Chemother. 2012;56(11):5790-5793.

49. Migliori GB, Eker B, Richardson MD, et al. A retrospective TBNET assessment of linezolid safety, tolerability and efficacy in multi-drug resistant tuberculosis. Eur Respir J. 2009;34(2):387-393.

50. Williams KN, Stover CK, Zhu T, et al. Promising antituberculosis activity of the oxazolidinone PNU-100480 relative to that of linezolid in a murine model. Antimicrob Agents Chemother. 2009;53(4):1314-1319.

51. William KN, Brickner SJ, Stover CK, et al. Addition of PNU-100480 to the first line drugs shortens the time needed to cure murine tuberculosis. Am J Respir Crit Care Med. 2009;180(4):371-376.
52. Swindells S. New drugs to treat tuberculosis. F1000 Med Rep. 2012;4: 12.

53. Wallis RS, Rodney Dawson, Sven O. Friedrich, Amour Venter, Darcy Paige, et al. (2014) Mycobacterial activity of Sutezolid (PNU-100480) in sputum (EBA) and blood (WBA) of patients with pulmonary tuberculosis. PLoS One. 9(4):e94462.

54. Barbachyn MR, Hutchinson DK, Brickner SJ, et al. Identification of a novel oxazolidinone (U-1004800) with potent antimycobacterial activity. J Med Chem. 1996;39(3):680-685.

55. Wallis RS, Jakubiec W, Kumar V, et al. Biomarker assisted dose selection for safety and efficacy in early development of PNU-100480 for tuberculosis. Antimicrob Agents Chemother. 2011;55(2):567-574.

56. Zhu T, Friedrich SO, Diacon A, et al. Population pharmacokinetic/ pharmacodynamic analysis of the bactericidal activities of sutezolid (PNU-100480) and its major metabolite against intracellular Mycobacterium tuberculosis in ex vivo Whole Blood cultures of patients with pulmonary tuberculosis. Antimicrob Agents Chemother. 2004;58(6):3306-3311.

57. Balasubramanian V, Solapure $\mathrm{S}$, Iyer $\mathrm{H}$, et al. Bactericidal activity and mechanism of action of AZD5847, a novel oxazolidinonefor treatment of tuberculosis. Antimicrob Agents Chemother. 2014;58(1):495-502.

58. Shaharyar M, Siddiqui AA, Ali MA, et al. Synthesis and invitro antimycobacterial activity of $\mathrm{N}^{1}$-nicotinoyl-3-(4'-hydroxy-3'-methyl phenyl)-5-[(sub)phenyl]-2-pyrazolines. Bioorg Med Chem Lett. 2006;16(15):3947-3949

59. Zitouni GT. Synthesis and anti-tuberculosis activity of new thiazolylhydrazone derivatives. European Journal of Medicinal Chemistry. 2009;43:981-985.

60. Herzigová $\mathrm{P}, \mathrm{K}$ limesová $\mathrm{V}$, Palát $\mathrm{K}$, et al. Preparation and in-vitro Evaluation of 4-Benzylsulfanylpyridine-2-carbohydrazides as potential antituberculosis agent. Arch Pharm Chem Life Sci. 2009;342(7):394404

61. Dinakaran M, Senthilkumar P, Yogeeswari P, et al. Antitubercular activity of novel benzothiazolo naphthyridone carboxylic acid derivatives endowed with high activity toward multi-drug resistant tuberculosis. Biomed Pharmacother. 2009;63(1):11-18.

62. Sriram D, Perumal Yogeeswari, Palaniappan Senthilkumar, et al. 5-nitrothiazolylthiosemicarbazones: Synthesis and antimicrobial evaluation against tubercular and non-tubercular mycobacterial species. Journal of Enzyme inhibition and Medicinal Chemistry. 2010;25(1):105110.

63. Manikannan R. Selective one-pot multicomponent synthesis and antitubercular evaluation of 5-(aryl/cyclohexylsulfanyl)-2-alkoxy-4,6diarylnicotinonitriles. Bioorg Med Chem Lett. 2010;20:3352-3355.

64. Ramani AV, Monika A, Indira VL,e t al. Synthesis of highly potent novel anti-tubercular isoniazid analogues with premilinary pharmacokinetic evaluation. Bioorg Med Chem Lett. 2010;22(8):2764-2767.

65. Rodriques MO, Cantos JB, D'Oca CR, et al. Synthesis and antimycobacterial activity of Isoniazid derivatives from renewable fatty acid. Bioorg Med Chem. 2013;21(22):6910-6914.

66. Odingo J, O’Malley T, Kesicki EA, et al. Synthesis and evaluation of the 2,4-diaminoquinazoline series as anti-tubercular agents. Bioorg Med Chem. 2014;22(24):6965-6979.

67. Sotgiu G, Centis R, D'Ambrosio L, et al. Efficacy, safety and tolerability of linezolid containing regimens in treating MDR-TB and XRD-TB : systematic review and meta-analysis. Eur Respir J. 2012;40(6):1430 1442 .

68. Lee M, Lee J, Carroll MW, et al. Linezolid for treatment of chronic extensively drug-resistant tuberculosis. NEngl Med.2012;367(16):15081518 . 
69. De LS, Alffenaar JW, Sotgiu G, et al. Effecacy and safety of meropenem/ clavulanate added to linezolid containing regimens in the treatment of MDR/XDR-TB. Eur Respir J. 2013;41(6):1386-1392.

70. Alsaad N, van Altena R, Pranger AD, et al. Evaluation of co-trimoxazole in treatment of multi-drug resistant tuberculosis. Eur Respir J. 2013;42(2):504-512.
71. Gillespie SH, Crook AM, McHugh TD, et al. Four-month Moxifloxacinbased regimens for drug-sensitive tuberculosis. $N$ Engl $\mathrm{J} \mathrm{Med}$. 2014;371(17):1577-1587.

72. Maitra A, Bates S, Shaik M, et al. Repurposing drugs for treatment of tuberculosis: a role for non-steroidal anti-inflammatory drugs. $\mathrm{Br} \mathrm{Med}$ Bull. 2016;118(1):136-148. 